\title{
Quality of Life After Sex Reassignment Surgery: A Systematic Review and Meta-Analysis
}

\author{
Samira Ebrahimzadeh Zagami (iD) ${ }^{1}$, Robab Latifnejad Roudsari (iD ${ }^{1,2,{ }^{*}}$ and Ramin Sadeghi (ii) ${ }^{3}$ \\ ${ }^{1}$ Nursing and Midwifery Care Research Center, Mashhad University of Medical Sciences, Mashhad, Iran \\ ${ }^{2}$ Department of Midwifery, School of Nursing and Midwifery, Mashhad University of Medical Sciences, Mashhad, Iran \\ ${ }^{3}$ Nuclear Medicine Research Center, Mashhad University of Medical Sciences, Mashhad, Iran \\ "Corresponding author: Professor in Reproductive Health, Department of Midwifery, School of Nursing and Midwifery, Mashhad University of Medical Sciences, Mashhad, Iran. \\ Emails: latifnejadr@mums.ac.ir; rlatifnejad@yahoo.com
}

Received 2018 April 04; Revised 2019 May 26; Accepted 2019 June 04.

\begin{abstract}
Context: Gender identity disorder (GID) or gender dysphoria is a disorder in which an individual identifies him/herself with the opposite sex. GID following sex reassignment surgery (SRS) is usually associated with severe distress and several limitations in the personal and social aspects of life as a transgender.

Objectives: The current systematic review and meta-analysis aimed at evaluating the quality of life (QoL) after SRS in transgender individuals.

Data Sources: A search was conducted in English databases, including PubMed, Scopus, PsycINFO, ScienceDirect, and Google Scholar. In addition, the reference lists of the included articles were reviewed without any time limitations. The final literature search was performed on 12 June 2017.

Study Selection: All relevant cross sectional and observational studies were evaluated in the current review. The keywords included sex, gender, reassignment surgery, reassignment operation, sex change, sex reversal, transpersonal, sexual transition, gender dysphoria, transsexual, transgender, gender identity, male-to-female transsexual, female-to-male transsexual, quality of life, QoL, quality adjusted, and wellbeing.

Data Extraction: After screening 941 articles, 16 studies were reviewed systematically, six of which were included in the metaanalysis. Comprehensive Meta-Analysis Software version 2 was used for all meta-analyses.

Results: QoL improved after SRS in some dimensions, including bodily pain, emotional role, and mental health in male-to-female (MtF) transsexuals, and physical function and physical role in female-to-male (FtM) transsexuals. Physical role, vitality, and social function in MtF transsexuals were not significantly different from the general population. In other words, bodily pain, general health, social function, vitality, mental health, and emotional role in FtM transsexuals, as well as physical function and general health in MtF transsexuals, were lower than the general population.

Conclusions: Based on the findings, SRS could improve some dimensions of QoL, including bodily pain, emotional role, and mental health in MtF transsexuals, and physical function as well as physical role in FtM transsexuals. Nevertheless, further research is necessary in this area.
\end{abstract}

Keywords: Gender Dysphoria, Quality of Life, Sex Reassignment Surgery, Systematic Review, Meta-Analysis

\section{Context}

Gender identity disorder (GID), gender dysphoria, or transsexualism are terms defined by the diagnostic and statistical manual of mental disorders (DSM) to describe an individual's continuous distress about his/her biological sex or assigned gender $(1,2)$. The International Classification of Diseases (ICD) has defined transsexualism as a complex mental disorder(3). Although the major causes of GID are not completely understood, genetics, psychosocial factors, and neurodevelopment might be involved (1). GID is potentially associated with the high prevalence of anxiety disorders, mood disorders, and suicidality in adults (1). In a meta-analysis, the prevalence of transsexualism was 4.6 per 100,000 individuals, i e, 6.8 for male-to-female (MtF) and 2.6 for female-to-male (FtM) transsexuals (2). Iran is the first country in the Middle East and the second country in the world following Thailand to perform sex reassignment surgery $(\mathrm{SRS})(4,5)$.

In many countries, transsexual people are treated according to the standards of care by Harry Benjamin International Gender Dysphoria Association (6). Treatment for 
transsexual people includes a set of hormonal and surgical procedures, which changes the physical appearance and function of sexual organs in order to facilitate transition to the opposite sex (7).

SRS is a surgical procedure usually necessary for both $\mathrm{MtF}$ and FtM transsexuals in order to reduce their distress caused by physical appearance. SRS, as a controversial medical intervention, is performed in $29 \%$ - 93\% of transsexuals, using different methods $(8,9)$. This intervention, which involves psychological, social, and legal aspects, is the most important step in changing the sexual characteristics of a transsexual individual to resemble those of the opposite gender $(9,10)$. SRS in MtF transsexuals involves implantation of breast prostheses, construction of a neovagina and clitoris, and other feminizing surgeries. On the other hand, surgeries for FtM transsexuals include hysterectomy with bilateral oophorectomy, construction of the neophallus, and mastectomy $(11,12)$. SRS is performed as part of the treatment of transsexuality for more than 70 years (13). It is also part of the treatment allowed in Iran since 1964 for transsexuality (14).

Some articles reported improvements in the surgical outcomes and quality of life (QoL) in transsexual individuals undergoing surgery (15-20). QoL includes different aspects of mental health, physical and social functions, and satisfaction (21). On the other hand, SRS may lead to several limitations in the personal and social life aspects of transgender individuals. According to the literature, this procedure can reduce the individual's social capital and QoL.

In this regard, Javaheri and Hoseinzadeh reported that the mean social capital and QoL of transsexual individuals were lower than expected (22). On the other hand, several studies demonstrated that transsexuals have a higher QoL (13, 23-25) and personal satisfaction (26-28) after genital surgery. In a study, Vasegh Rahimparvar et al., reported that the QoL of MtF transsexuals was similar to that of ordinary females (29).

\section{Objectives}

Individuals who are candidates for SRS have little information about the overall outcomes and QoL following the surgery. Also, experts who serve as consultants for these cases have inadequate knowledge in this area (13). Despite the long history of treatment for transsexuality, there is a scarcity of information regarding its psychiatric morbidities (30). Some studies show that SRS has a positive effect on the individual's wellbeing and sexual function $(20,31$, 32 ). However, the outcomes of SRS vary in different countries and cultures. Therefore, the current systematic review and meta-analysis aimed at reviewing the literature, and evaluating different dimensions of QoL after SRS in transgender individuals.

\section{Data Sources}

\subsection{Search Strategy}

The current systematic review and meta-analysis included all articles published worldwide in the area of QoL after SRS. The search in the current study had no language limitation; however, all the three non-English language articles found by search were excluded based on their abstracts. A search was conducted in English databases, including PubMed, Scopus, PsycINFO, ScienceDirect, and Google Scholar in accordance with the PRISMA 2009 checklist without any time limitations. The final literature search was performed on 12 June 2017.

The authors used a search strategy by combining MeSH terms and keywords used in the article titles and abstracts. The keywords included sex OR gender AND reassignment surgery OR reassignment operation OR reassigned OR sex change OR sex reversal OR transpersonal OR sexual transition OR gender dysphoria OR transsexualism OR transsexual OR transgender OR gender identity OR male-to-female OR female-to-male OR MtF OR FtM AND quality of life OR QoL OR quality adjusted OR wellbeing. The reference lists of potentially relevant articles were also searched in order to find other possibly relevant studies.

\section{Study Selection}

In the current review study, all articles examining MtF and/or FtM transsexuals undergoing SRS in terms of QoL were retrieved. Studies were included regardless of the sample size, age of the participants, follow-up duration, or type of transsexualism. Two reviewers examined all titles and abstracts, simultaneously. Discrepancies between the reviewers were resolved by the third reviewer.

The exclusion criteria for articles were: (1) inadequate documentation of the methodology or results; (2) articles irrelevant to the topic of the study; (3) review articles, qualitative studies, editorials or letters, commentaries, case reports, dissertations, or conference proceedings; (4) duplicate publications; and (5) studies focused on the physical and psychological complications of transsexual people.

\subsection{Quality Assessment}

The methodological quality of studies was assessed by two authors independently, and disagreements were resolved by consensus. The 22-item STROBE 2007 (version 4) checklist (33) was used for the quality assessment of studies, with yes/no questions ("Yes/Y", presence of the item; "No/N", absence of the item). The total score is the sum of positive answers. Cohort studies scored $\geq 7$, as well as cross sectional studies scored $\geq 6$ were considered as highquality. In the current review, all included studies were of high-quality (34) (Table 1). 


\section{Data Extraction}

The following information was abstracted for each study: authors' names, year of study, study setting, study design, population description (MtF or FtM transsexuals), mean sample age, sample size, instruments, and treatment duration (Table 2). In addition, QoL was extracted for each study (Table 3).

\subsection{Statistical Analysis}

A meta-analysis of studies reporting adequate quantitative data after SRS was conducted. The main effect size indicated the difference in the mean scores of QoL after surgery. Forest plots were depicted for graphic presentation of the results (Figures 1 and 2). Cochrane Q test was also used to evaluate heterogeneity and P values less than 0.05 were considered statistically significant. The $I^{2}$ index was also used to quantify heterogeneity. Data pooling was carried out separately for each aspect of QoL in transsexual females and males (six meta-analyses). The calculation was conducted using Comprehensive Meta-Analysis Software version 2. Meta-analyses were performed independently for FtM and MtF transsexuals.

\section{Results}

The literature search indicated 941 articles. The fulltexts of 46 studies were screened after reviewing the articles based on their titles and abstracts, removing duplicate and irrelevant articles (deletion of 746 articles), and assessing the articles in detail (deletion of 149 articles). Finally, according to the inclusion criteria (deletion of 32 articles), 16 articles were retrieved in the current systematic review, and only six studies were included in the metaanalysis (Figure 3). In addition, one more article was found by checking the reference lists of the included articles.

Out of 16 studies, two were conducted in the USA (24, $44)$, three in Belgium $(40,41,43)$, two in Iran $(22,29)$, one in Switzerland (13), one in the UK (37), one in Croatia (38), one in Yugoslavia (25), one in France (42), one in Brazil (35), one in the Netherlands (39), one in Germany (10), and one in Italy (36). Six studies had a cross sectional design (22, 24, 29, $40,41,43)$, four were case-control studies $(10,13,36,37)$, four were cohorts $(25,35,39,44)$, and two had a mixed-methods design (quantitative data were assessed) $(38,42)$.

The samples in the review included a total of 1449 FtM and MtF transsexuals (768 MtF and 681 FtM transsexuals). Hormonal therapy was administered in transsexuals in 10 studies (67\% to $100 \%$ ). Based on the findings, SRS was performed from six months to 22 years ago. The mean age of the subjects ranged 20.5 to 37.3 years in FtM transsexuals and 21 to 56.9 years in MtF transsexuals.
QoL was measured using the short-form health survey (SF-36) in eight studies $(24,29,37,38,40-43)$, WHOQOLBREF questionnaire in three studies $(35,36,39)$, King's health questionnaire in one study (13), self-structured instruments in two studies $(22,25)$, a standardized selfassessment tool for QoL in one study (10), and a 21-point Likert scale in one study (44). Out of 15 studies evaluating the QoL, nine examined both FtM and MtF transsexuals (13, 22, $25,36-40,45)$, two focused on FtM transsexuals $(24,41)$, and four examined MtF transsexuals $(29,35,43,44)$. Also, there was a control group in eight studies $(13,24,29,36,37,40,41$, 43). QoL was evaluated before and after the surgery in only two studies $(25,35)$.

In terms of demographic variables, the number of single subjects was higher in MtF transsexuals compared to normal females $(\mathrm{P}<0.09)$ (29). In fact, the number of married transsexuals was significantly lower than the general population $(P=0.019)$ (13). In addition, the level of income and insurance coverage were lower in MtF transsexuals compared to normal females $(\mathrm{P}<0.05)(29)$; nevertheless, in a study, $74.8 \%$ of FtM transsexuals were under insurance converge (24). According to two studies, the level of education was high-school diploma or higher in $88 \%$ of FtM transsexuals and $89 \%$ of all transsexuals $(24,45)$.

Figures 1 and 2 represent the meta-analyses of mean differences in multiple aspects of QoL in comparison with the controls. General health was not significantly different between MtF transsexuals and the controls. Additionally, all aspects of mental health were significantly lower in FtM transsexuals rather than controls, except for physical role and bodily pain. Modarresi Fard et al., found that SRS can improve the QoL and physical and psychological health of individuals with GID (45). A study also reported that participants who received testosterone had a higher QoL (24). In another study, it was revealed that the level of education had a direct correlation with three dimensions of QoL (i e, physical function, mental health, and social functioning) in transsexuals (22), while another study did not report any significant differences between MtF transsexuals and normal females (29). Also, there was no significant difference between MtF transsexuals and the control group in terms of the mean age (29).

Social functioning, emotional role, and mental health were significantly lower in FtM transsexuals aged 44 years or younger, compared to normal males and females. Conversely, physical health was not significantly different between FtM transsexuals and females in any age group (24). Newfield et al., also found no significant difference in the duration of surgery (24). 


\begin{tabular}{|c|c|c|c|c|c|c|c|c|c|}
\hline Study & Country & Year & Study Design & $\begin{array}{l}\text { MtF or FtM } \\
\text { Transsexuals }\end{array}$ & $\begin{array}{l}\text { Intervention/Control } \\
\text { Group }\end{array}$ & Mean Age, $y$ & Instrument & Hormonal Status & Treatment \\
\hline $\begin{array}{l}\text { Papadopulos et } \\
\text { al. (10) }\end{array}$ & Germany & 2017 & Retrospective study & $\begin{array}{c}\text { 47 MTF } \\
\text { transsexuals }\end{array}$ & $\begin{array}{l}\text { Results were } \\
\text { compared with } \\
\text { normative data }\end{array}$ & $38.3(18-57)$ & $\begin{array}{l}\text { A standardized } \\
\text { self-assessment test } \\
\text { on QoL }\end{array}$ & $\begin{array}{l}\text { Use of hormone } \\
\text { cream }\end{array}$ & $\begin{array}{c}\text { SRS was performed } \\
\text { between } 2007 \text { and } \\
2013 .\end{array}$ \\
\hline $\begin{array}{l}\text { Cardoso da Silva } \\
\text { et al. (35) }\end{array}$ & Brazil & 2016 & $\begin{array}{l}\text { Prospective cohort } \\
\text { study }\end{array}$ & $47 \mathrm{MtF}$ transsexual & $\begin{array}{l}47 \mathrm{MtF} \text { before and } \\
\text { after SRS }\end{array}$ & $31.23(16-54)$ & $\begin{array}{l}\text { The WHOQOL-100 } \\
\text { questionnaire }\end{array}$ & $100 \%$ & $\begin{array}{l}\text { SRS, hormonal } \\
\text { therapy, and } \\
\text { supportive group } \\
\text { therapy }\end{array}$ \\
\hline $\begin{array}{l}\text { Castellano et al. } \\
(36)\end{array}$ & Italy & 2015 & Case-control study & $\begin{array}{l}60 \text { transsexuals ( } 46 \\
\text { MtF transsexuals, } 14 \\
\text { FtM transsexuals) }\end{array}$ & $\begin{array}{l}60 \text { transsexuals, } 60 \\
\text { matched controls }\end{array}$ & $39.0(18-65)$ & WHOQOL-100 test & $100 \%$ & $\begin{array}{c}\text { SRS at least } 2 \text { years } \\
\text { ago and hormonal } \\
\text { therapy }\end{array}$ \\
\hline Davey et al. (37) & The UK & 2014 & Case-control study & $\begin{array}{l}103 \text { individuals } \\
\text { with gender } \\
\text { dysphoria ( } 63 \\
\text { females and } 40 \\
\text { males) }\end{array}$ & $\begin{array}{l}103 \text { individuals } \\
\text { with an age and } \\
\text { gender matched } \\
\text { non-clinical } \\
\text { control group }\end{array}$ & $36.4(18-72)$ & SF-36 (version 2) & $\begin{array}{l}\text { No use: } 19(18.5 \%) \\
\text { Current use: } 81 \\
(78.6 \%) ; \text { Previous } \\
\text { use: } 1(1 \%)\end{array}$ & $\begin{array}{l}\text { All participants } \\
\text { were involved in } \\
\text { the treatment at } \\
\text { one of three phases } \\
\text { of assessment, } \\
\text { real-life experience } \\
\text { (RLE), or } \\
\text { post-surgery". }\end{array}$ \\
\hline $\begin{array}{l}\text { Jokic-Begic et al. } \\
\text { (38) }\end{array}$ & Croatia & 2014 & $\begin{array}{l}\text { Quantitative and } \\
\text { qualitative } \\
\text { self-report } \\
\text { methods }\end{array}$ & $\begin{array}{c}3 \mathrm{MtF} \text { transsexuals } \\
\text { and } 3 \mathrm{FtM} \\
\text { transsexuals }\end{array}$ & - & 33.8 & The SF-36 & NR & $\begin{array}{l}\text { SRS in the last } 15 \\
\text { years }\end{array}$ \\
\hline de Vries et al. (39) & The Netherlands & 2014 & Longitudinal study & $\begin{array}{l}22 \mathrm{MtF} \text { transsexuals } \\
\text { and; } 33 \mathrm{FtM} \\
\text { transsexuals }\end{array}$ & - & $21 ; 20.5$ & $\begin{array}{l}\text { The WHOQOL-BREF } \\
\text { (quality of life } \\
\text { measure developed } \\
\text { by the World } \\
\text { Health } \\
\text { Organization) }\end{array}$ & $100 \%$ & $\begin{array}{l}\text { At least } 1 \text { year after } \\
\text { GRS }\end{array}$ \\
\hline $\begin{array}{l}\text { Motmans et al. } \\
\text { (40) }\end{array}$ & Belgium & 2012 & Cross sectional & $\begin{array}{l}77 \mathrm{MtF} \text { transsexuals } \\
\text { and; } 63 \mathrm{FtM} \\
\text { transsexuals }\end{array}$ & - & $42.26 ; 37.03$ & $S F-36$ & $\begin{array}{l}58(96.7 \%) \text { in } \\
\text { transmale and } 70 \\
(94.6 \%) \text { in } \\
\text { transfemale }\end{array}$ & $\begin{array}{l}\text { Hormonal therapy } \\
\text { and trans-related } \\
\text { surgery were not in } \\
\text { the year of the } \\
\text { study }\end{array}$ \\
\hline $\begin{array}{l}\text { Vasegh } \\
\text { Rahimparvar et } \\
\text { al. (29) }\end{array}$ & Iran & 2012 & Cross sectional & $46 \mathrm{MtF}$ transsexuals & 184 women & NR & SF-36 & $\mathrm{NR}$ & $\begin{array}{l}\text { At least 1 year after } \\
\text { GRS }\end{array}$ \\
\hline Wierckx et al. (41) & Belgium & 2011 & $\begin{array}{l}\text { A single center, } \\
\text { cross sectional }\end{array}$ & 49 transmale & $\begin{array}{l}976 \text { Dutch males } \\
\text { and } 976 \text { Dutch } \\
\text { females }\end{array}$ & $37(22-54)$ & $\begin{array}{l}\text { Dutch version of } \\
\text { the SF-36 }\end{array}$ & $\begin{array}{l}100 \% \text { At least } 2 \\
\text { years before SRS }\end{array}$ & $\begin{array}{l}\text { SRS between } 1987 \\
\text { and 2009; All } \\
\text { participants } \\
\text { underwent SRS } \\
\text { (hystero- } \\
\text { oophorectomy and } \\
\text { mastectomy); } 8 \\
\text { years ago on } \\
\text { average }(2-22 \\
\text { years) }\end{array}$ \\
\hline $\begin{array}{l}\text { Javaheri and } \\
\text { Hosseinzadeh (22) }\end{array}$ & Iran & 2011 & Cross sectional & $\begin{array}{l}93 \mathrm{MtF} \text { transsexuals } \\
\text { and } 75 \mathrm{FtM} \\
\text { transsexuals }\end{array}$ & . & 26 & $\begin{array}{l}\text { Self-structured } \\
\text { questionnaire }\end{array}$ & $\mathrm{NR}$ & $\mathrm{NR}$ \\
\hline Parola et al. (42) & France & 2010 & A personality study & $\begin{array}{l}15 \mathrm{MtF} \text { transsexuals } \\
\text { and; } 15 \mathrm{FtM} \\
\text { transsexuals }\end{array}$ & - & & SF-36 & . & $\begin{array}{l}\text { Hormonal-surgical } \\
\text { reassignment at } \\
\text { least } 2 \text { years ago }\end{array}$ \\
\hline Kuhn et al. (13) & Switzerland & 2009 & Case-control & $\begin{array}{c}52 \mathrm{MtF} \text { transsexuals } \\
\text { and; } 3 \mathrm{FtM} \\
\text { transsexuals }\end{array}$ & 20 controls & 51 & King' s Health & $100 \%$ & SRS 15 years ago \\
\hline Weyers et al. (43) & Belgium & 2009 & Cross sectional & $50 \mathrm{MtF}$ transsexuals & 766 females & 43.06 & $S F-36$ & $94 \%$ & $\mathrm{SRS} \geq 6 \mathrm{mn}$ \\
\hline $\begin{array}{l}\text { Newfield et al. } \\
\text { (24) }\end{array}$ & The USA & 2006 & Cross sectional & $\begin{array}{c}376 \mathrm{FtM} \\
\text { transsexuals }\end{array}$ & $\begin{array}{l}\text { The US general } \\
\text { population }\end{array}$ & 32.8 & $\begin{array}{l}\text { SF-36 (during or in } \\
\text { the past } 4 \text { weeks) }\end{array}$ & $\begin{array}{l}67 \% \text { received } \\
\text { testosterone }\end{array}$ & $\begin{array}{c}\text { Testosterone } \\
\text { therapy and/or SRS }\end{array}$ \\
\hline Lawrence (44) & The USA & 2006 & Prospective study & $\begin{array}{c}232 \mathrm{MtF} \\
\text { transsexuals }\end{array}$ & - & 47 & 21-point Likert scale & $100 \%$ & . \\
\hline Rakic et al. (25) & Yugoslavia & 1996 & A follow-up study & $\begin{array}{l}22 \mathrm{MtF} \text { transsexuals } \\
\text { and } 10 \mathrm{FtM} \\
\text { transsexuals }\end{array}$ & . & $\begin{array}{l}26.36 \mathrm{in} \mathrm{MtF} \\
\text { transsexuals and } \\
27.8 \text { in FtM } \\
\text { transsexuals }\end{array}$ & $\begin{array}{l}\text { Self-structured } \\
\text { questionnaire }\end{array}$ & . & . \\
\hline
\end{tabular}

Abbreviations: GRS, gender reassignment surgery; FFS, facial feminization surgery; SF-36, 36-item short form; SRS, sex reassignment surgery.

\section{Discussion}

The current systematic review and meta-analysis was conducted to evaluate QoL in transsexual individuals undergoing SRS. The results showed that some dimensions of QoL were not significantly different between individuals undergoing SRS and the general population. QoL improved following SRS in some dimensions, including bod- ily pain, emotional role, and mental health in MtF transsexuals and physical function and physical role in FtM transsexuals. Conversely, bodily pain, general health, social function, vitality, mental health, and emotional role were lower in FtM transsexuals compared to the general population, similar to physical function and general health in MtF transsexuals.

Although gender had a major influence on the find- 


\begin{tabular}{|c|c|}
\hline Study & Quality of Life \\
\hline Papadopulos, et al., 2017 (10) & Improvement of QoL was experienced by $91 \%$ after SRS \\
\hline Cardoso da Silva et al., 2016 (35) & $\begin{array}{l}\text { After SRS psychological and social relationships improved and physical health and level of independence worsened. The } \\
\text { environment, and spirituality, religion and personal beliefs domains did not change }\end{array}$ \\
\hline Castellano et al., 2015 (36) & The QoL scores in transsexuals were similar to those of the matched controls \\
\hline Davey et al., 2014 (37) & $\begin{array}{l}\text { Individuals with gender dysphoria displayed higher psychopathology, and lower QoL and life satisfaction compared with } \\
\text { controls }\end{array}$ \\
\hline Jokic-Begic et al., 2014 (38) & 3 transsexual individuals had lower QoL \\
\hline \multirow[t]{4}{*}{ de Vries et al., 2014 (39) } & WHOQOLa physical: mean (SD): $15.22(2.49)$ \\
\hline & WHOQOL psychological: $14.66(2.44)$ \\
\hline & WHOQOL social relations: mean (SD): $14.91(2.35)$ \\
\hline & WHOQOL environment: mean (SD): 15.47 (2.06) \\
\hline Modarresi Fard et al., 2014 (45) & $\begin{array}{l}\text { The results showed that from the QoL dimensions, physical health }(\mathrm{P}<0.000) \text {, psychological QoL }(\mathrm{P}<0.005) \text {, and the gender } \\
\text { roles of patients were significantly different before and after SRS }\end{array}$ \\
\hline \multirow[t]{2}{*}{ Motmans et al., $2012(40)$} & $\begin{array}{l}\text { The QOL of transgender females did not differ significantly from the general Dutch female population, although transgender } \\
\text { males showed reduced mental health-related QoL compared to the general Dutch male sample }\end{array}$ \\
\hline & $\begin{array}{l}\text { Transgender females had a lower QoL than transgender males for the subscales physical functioning and general health, but } \\
\text { better QoL for bodily pain }\end{array}$ \\
\hline \multirow[t]{2}{*}{ Vasegh Rahimparvar et al., 2012 (29) } & Mean total score of QoL was $69.98 \pm 17.4$ and $68.87 \pm 15.3 \mathrm{in} \mathrm{MtF}$ transsexuals and controls $(\mathrm{P}=0.594)$ \\
\hline & The physical pain was higher in MtF transsexuals than controls $(\mathrm{P}=0.01)$ \\
\hline \multirow[t]{3}{*}{ Javaheri and Hosseinzadeh 2011 (22) } & Only $20 \%$ of transsexuals were highly satisfied \\
\hline & $10 \%$ had a good level of mental health \\
\hline & QoL was $29.51 \pm 12.41$ and $36.445 \pm 12.28$ in MtF transsexuals and FtM transsexuals, respectively $(\mathrm{P}<0.001)$ \\
\hline \multirow[t]{2}{*}{ Wierckx et al., 2011 (41) } & Transsexual males generally had a good QoL and experienced satisfactory sexual function after SRS. \\
\hline & $\begin{array}{l}\text { Physical functioning: } 85.9 \text {, role-physical: } 83.3 \text {, bodily pain: } 75.8 \text {, general health: } 70.9 \text {, vitality: } 62.1 \text {, social functioning: } 85.5 \text {, } \\
\text { role-emotional: } 83.0 \text {, mental health: } 72.6\end{array}$ \\
\hline Parola et al., 2010 (42) & SRS improved the QoL \\
\hline Weyers et al., 2009 (43) & $\begin{array}{l}\text { Engaged females got physical and mental component summary scores similar to those of transsexual females not currently } \\
\text { engaged, although engaged females got higher scores in vitality }(\mathrm{P}=0.049) \text {, social functioning }(\mathrm{P}=0.008) \text {, and mental } \\
\text { health }(\mathrm{P}=0.025)\end{array}$ \\
\hline \multirow[t]{5}{*}{ Newfield et al., 2006 (24) } & QoL and concept of health were lower among the FtM transgender \\
\hline & participants compared to those of the MtF population $(\mathrm{P}<0.01)$, particularly in mental health \\
\hline & $\begin{array}{l}\text { QoL reduced among the FtM transsexuals compared to the US males and females, particularly in mental health and social } \\
\text { functioning }\end{array}$ \\
\hline & Physical functioning and physical health scores were higher than the general population \\
\hline & Physical role and bodily pain in transsexuals were not different from those of the general population \\
\hline Rakic et al., 1996 (25) & QoL was significantly different before and after SRS. Interpersonal relationship was better after surgery \\
\hline
\end{tabular}

ings, the QoL dimensions in MtF transsexuals were similar to those of normal females, except for general health. On the other hand, QoL dimensions in FtM transsexuals were not similar to those of normal males, except for the dimensions of bodily pain and physical role. Therefore, it can be concluded that transsexual people have special needs and conditions that should be distinguished and taken into account.

Transsexuality and its impact on the individual's life are observed in all cultures. Gender identity is a part of human rights, and accordingly, care is provided for transsexuals in Western European countries, the USA, and developed countries in Eastern Asia (38). Nonetheless, Jokic Be- gic found that transsexual people do not receive adequate support and have insufficient access to treatment, as medical professionals have inadequate knowledge about transgender health care (38). Additionally, it is important to support the partners, families, and friends of transgender people (26).

The complications of SRS may necessitate additional surgeries, with possible long-term outcomes on the mental health of transsexual people. Overall, the number of required surgeries for SRS complications (or other related factors) is high in FtM transsexuals (47), as well as MtF ones (48). In this regard, a study showed that transsexual females have a lower mental burden than transsexual males 


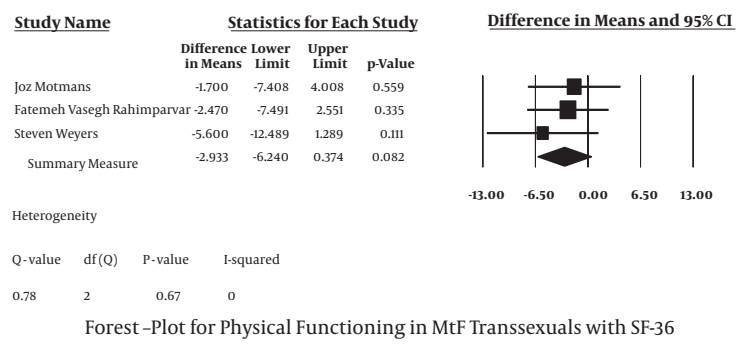

Study Name Statistics for Each Study Difference in Means and $95 \%$

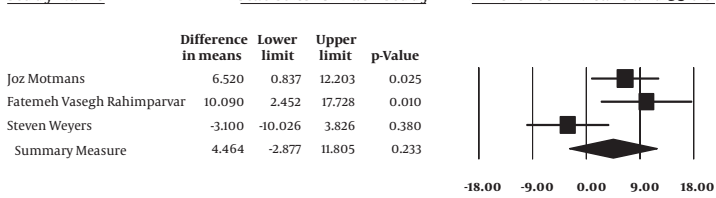

Heterogeneity

Q-valuedf $(Q) \quad$ P-value $\quad$ I-squared

Forest-Plot for Bodily Pain in MtF Transsexuals with SF-36

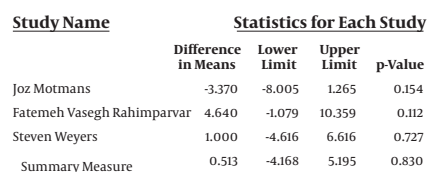

Summary Measu

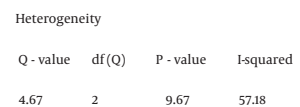

$\begin{array}{llll}4.67 & 2 & 9.67 & 57.18\end{array}$

Forest -Plot for Vitality in MtF Transsexuals with SF-36
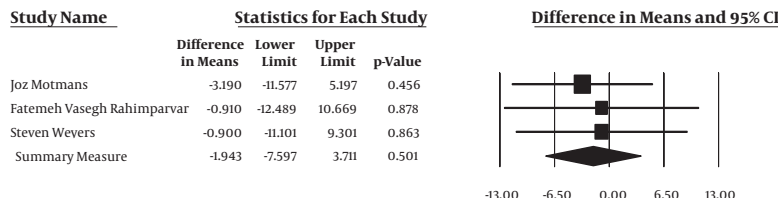

Heterogeneity

Q-value $\quad \mathrm{df}(\mathrm{Q}) \quad$ P-value $\quad$ I- squared

Forest-Plot for Role Emotional in MtF Transsexuals with SF-36

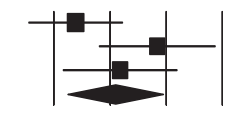

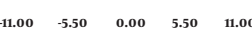

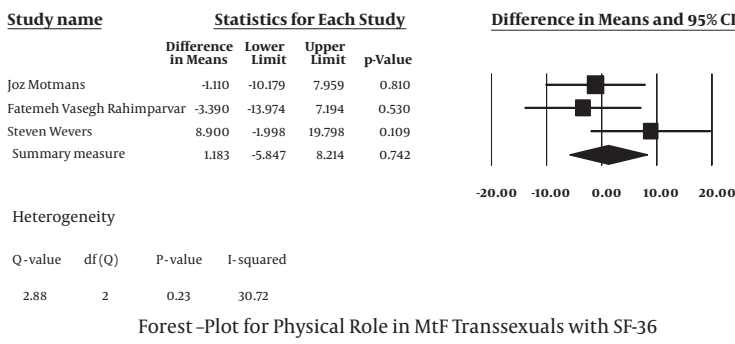

Study Nam

Statistics for Each Study Std diff Lower Upper

in Means Limit Limit p-Valu $\begin{array}{lrrrr} & \text { in Means } & \text { Limit } & \text { Limit } & \text { p-Value } \\ \text { Joz Motmans } & -0.116 & -0.350 & 0.118 & 0.332 \\ \text { Annette Kuhn } & -4.175 & -5.030 & -3.320 & 0.000 \\ \text { Fatemeh Vasegh Rahimparvar } & -0.078 & -0.402 & 0.245 & 0.635\end{array}$ $\begin{array}{lllll}\text { Fatemeh Vasegh Rahimparvar } & -0.078 & -0.402 & 0.245 & 0.635 \\ \text { Steven } & -0.218 & -0.504 & 0.068 & 0.135\end{array}$ Steven Weyers $\quad-0.218$ - $-0.504 \quad 0.068 \quad 0.135$ Summary Measure $\begin{array}{llll}-1.006 & -1.892 & -0.119 & 0.026\end{array}$ Std diff in Means and 95\% $\mathrm{CI}$

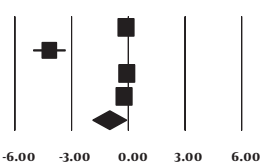

Heterogeneit

Q-value $\quad \mathrm{df}(\mathrm{Q}) \quad$ P-value $\quad$ I-squared

$\begin{array}{llll}83.27 & 3 & 0 & 96.39\end{array}$

Forest -Plot for General Health in MtF Transsexuals with SF-36

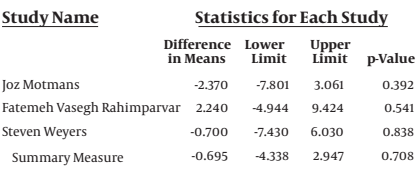

Difference in Means and $95 \% \mathrm{CI}$

Heterogeneity

Q-value $\quad \mathrm{df}(\mathrm{Q}) \quad$ P-value $\quad$-1-squared

$\begin{array}{llll}1.006 & 2 & 0.60 \quad 0\end{array}$

Forest-Plot for Social Functioning in MtF Transsexuals with SF-36

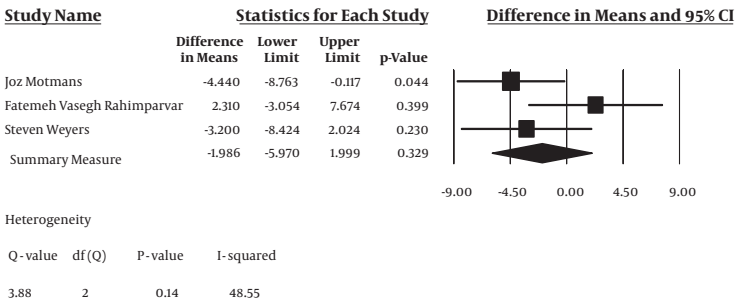

Forest -Plot for Mental Health in MtF Transsexuals with SF-36

Figure 1. The forest plot for dimensions of the quality of life in male-to-female transsexuals with SF-36

(40).

Additionally, demographic and socioeconomic characteristics have strong effects on the QoL of transsexual people. In this regard, Motmans et al., reported that age is negatively correlated with some dimensions of QoL, such as physical health. Moreover, they found that older transsexual people had lower SF-36 scores in some QoL dimensions, such as physical function and general health (40).
The QoL scores were significantly lower in transgender individuals with lower educational levels and household income, compared to those with higher education and household income. In addition, older, unemployed, and single transsexuals obtained lower QoL scores in comparison with younger, employed, and married transsexuals (40). Also, well-educated transsexuals could establish a better relationship with others and had a high QoL because 


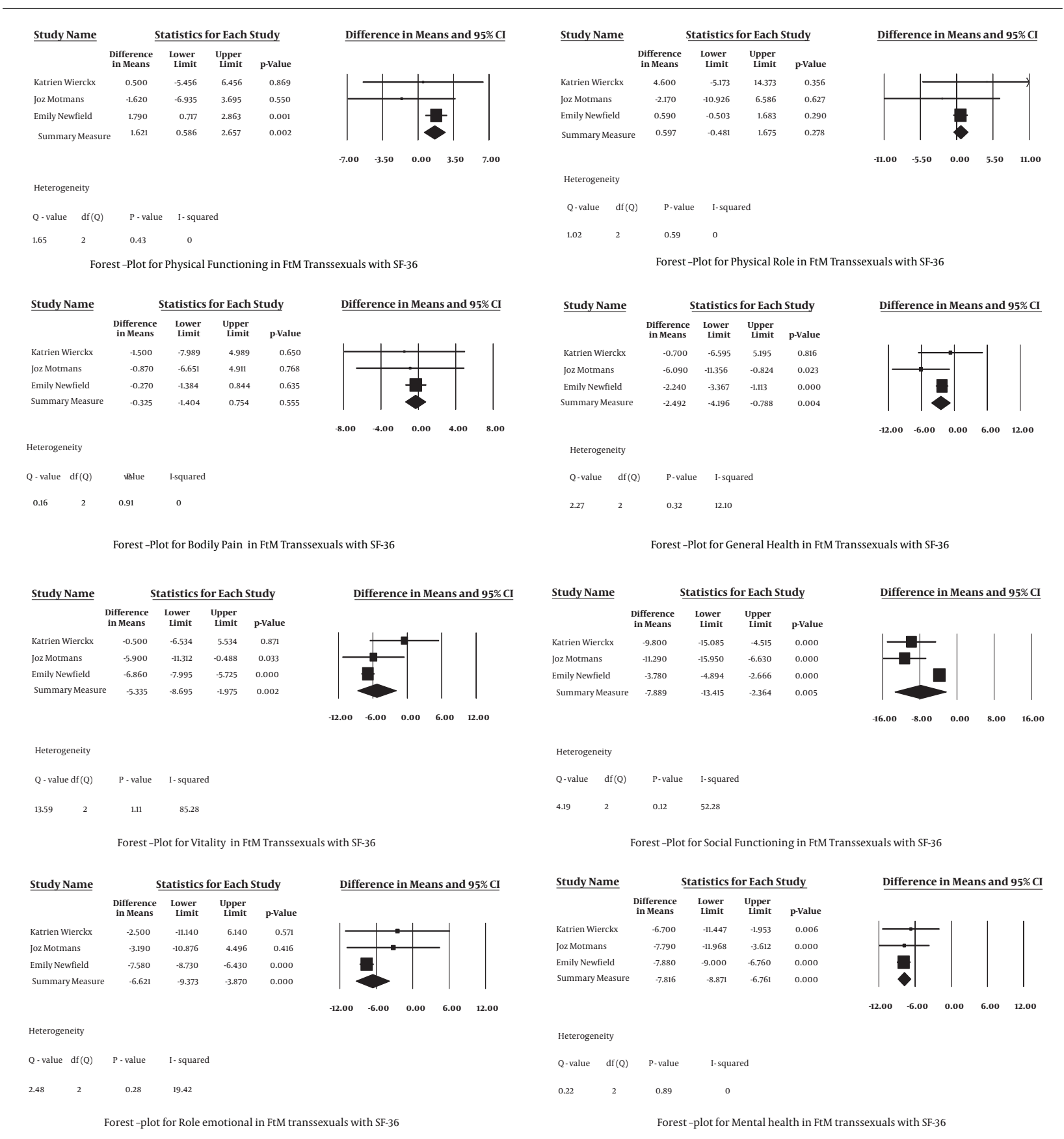

Figure 2. The forest plot for dimensions of the quality of life in female-to-male transsexuals with SF-36

of their extensive information in this area (22).

Some studies report that most transsexual people were single. However, the impact of civil status on QoL is a controversial topic, and its independent effects are not wellestablished (13). Based on the findings, FtM transsexuals ex- perience a greater reduction in physical health in comparison with normal males, whereas no significant difference was found between FtM transsexuals and females from the same age category; it can be attributed to the fact that FtM transsexuals are biologically female and physically similar 


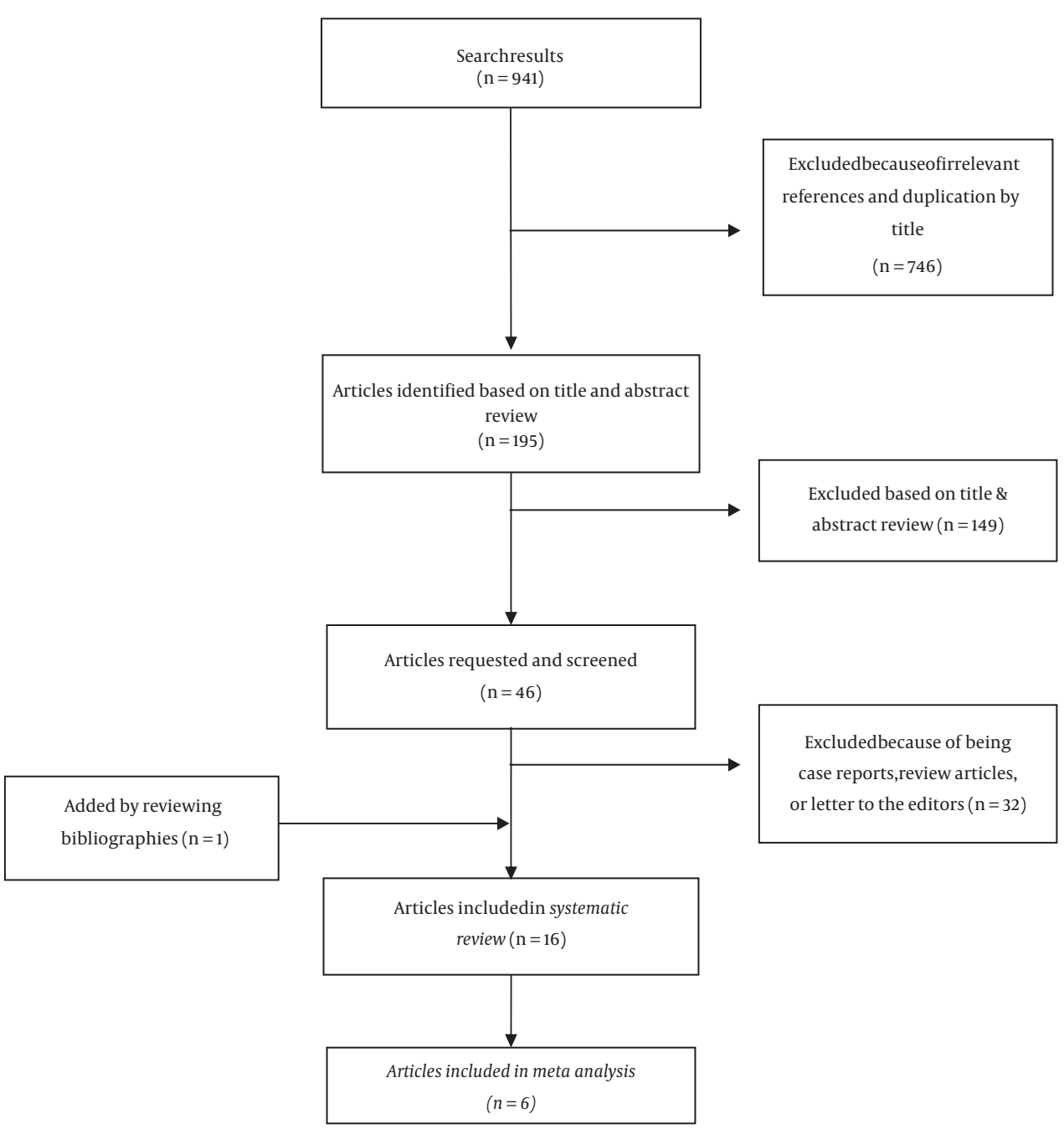

Figure 3. Article search strategy based on PRISMA guidelines (46)

to females, not males (24).

One of the strengths of the current study was that the literature search was carried out without any time limitations among publications. Also, QoL was assessed using validated tools in most studies, which could by itself strengthen the quality of these studies (13). On the other hand, a limitation of the study was that only the studies focusing on QoL as the main objective were retrieved; therefore, some studies might be missed. In addition, numerous search criteria were used in the current review in order to identify QoL after SRS in the published literature.

Another limitation of the study may be that many instruments were not transgender-specific and might have lower sensitivity. The number and design of retrieved studies were among other shortcomings. Selection bias should also be considered in the current systematic re- view, since transsexual people, who agreed to participate in these studies, might have more satisfaction and better outcomes, compared to individuals who did not accept to participate (41).

It should be noted that in most of the articles, data were not compared before and after hormonal therapy and SRS. As the current review indicated, some transsexual people used hormonal therapy before and after SRS in eight studies; therefore, hormonal therapy might have affected the results. In fact, the literature suggests that genderaffirming hormonal therapy can improve the QoL of transgender adolescents (49). Also publication bias could be a potential threat for the validity of the findings so that the results should be interpreted with more caution (50).

Overall, patients with GID should be diagnosed as early as possible, and SRS should be carried out at younger ages. 
It should be noted that transsexual people are a vulnerable group, requiring economic, social, medical, and family support. Also, it is recommended to investigate other factors influencing the QoL of such people; i e, cultural, religious, social, and demographic variables.

\section{Conclusions}

Based on the findings, there were no significant difference between MtF transsexuals after SRS and the general population in some dimensions of the QoL, including physical role, vitality, and social function. The dimensions of bodily pain, emotional role, and mental health improved in MtF transsexuals, while physical function and physical role improved in FtM transsexuals. However, no improvement was observed in other dimensions, such as physical function and general health in MtF transsexuals, as well as bodily pain, general health, social function, vitality, mental health, and emotional role in FtM transsexuals. Overall, several factors may affect the QoL in transsexual people, such as demographic characteristics, socioeconomic factors, and hormonal therapy. In the majority of studies, data were not compared before and after SRS; therefore, further studies are needed to examine all aspects of QoL before and after SRS in MtF and FtM transsexuals. Also, factors affecting the QoL in such individuals should be examined.

\section{Acknowledgments}

The authors acknowledge their gratitude to the library staff of Mashhad University of Medical Sciences, Mashhad, Iran, who helped them to carry out the systematic review through extensive search in different databases. We are also thankful to the vice chancellor for research at Mashhad University of Medical Sciences, Mashhad, Iran.

\section{Footnotes}

Authors' Contribution: Samira Ebrahimzadeh Zagami analyzed and interpretated the data. Samira Ebrahimzadeh Zagami, Robab Latifnejad Roudsari and Ramin Sadeghi drafted the manuscript. Samira Ebrahimzadeh Zagami revised critically the manuscript for important intellectual content. Samira Ebrahimzadeh Zagami, Robab Latifnejad Roudsari, and Ramin Sadeghi, analyzed statistically the data.

Declaration of Interest: Authors declared no conflict of interest.

Funding/Support: The study received financial support from the vice chancellor for research at Mashhad University of Medical Sciences, Mashhad, Iran.

\section{References}

1. Zucker KJ, Lawrence AA, Kreukels BP. Gender dysphoria in adults. Annu Rev Clin Psychol. 2016;12:217-47. doi: 10.1146/annurev-clinpsy021815-093034. [PubMed: 26788901].

2. Arcelus J, Bouman WP, Van Den Noortgate W, Claes L, Witcomb G, Fernandez-Aranda F. Systematic review and meta-analysis of prevalence studies in transsexualism. Eur Psychiatry. 2015;30(6):807-15. doi: 10.1016/j.eurpsy.2015.04.005. [PubMed: 26021270].

3. American Psychiatric Association. Diagnostic and statistical manual of mental disorders. Arlington: American Psychiatric Publishing; 2013. p. 451-9. doi: 10.1176/appi.books.9780890425596.

4. Najafipour M, Najafipour F. Transsexualism in Iran. Int J Sci Eng Res. 2018;9(1).

5. Saeidzadeh Z. The legality of sex change surgery and construction of transsexual identity in contemporary Iran [dissertation]. Lund University; 2015.

6. Cohen-Kettenis PT, Gooren LJ. Transsexualism: A review of etiology, diagnosis and treatment. J Psychosom Res. 1999;46(4):315-33. [PubMed: 10340231].

7. Gomez-Gil E, Zubiaurre-Elorza L, Esteva I, Guillamon A, Godas T, Cruz Almaraz M, et al. Hormone-treated transsexuals report less social distress, anxiety and depression. Psychoneuroendocrinology. 2012;37(5):662-70. doi: 10.1016/j.psyneuen.2011.08.010. [PubMed: 21937168].

8. Toivonen KI, Dobson KS. Ethical issues in psychosocial assessment for sex reassignment surgery in Canada. Can Psychol. 2017;58(2):178. doi: 10.1037/cap0000087.

9. Sangganjanavanich VF. Sex reassignment surgery. In: Naples NA, editor. The Wiley Blackwell encyclopedia of gender and sexuality studies. 2016.

10. Papadopulos NA, Lelle JD, Zavlin D, Herschbach P, Henrich G, Kovacs L, et al. Quality of life and patient satisfaction following maleto-female sex reassignment surgery. J Sex Med. 2017;14(5):721-30. doi: 10.1016/j.jsxm.2017.01.022. [PubMed: 28366591].

11. Gooren LJ. Clinical practice. Care of transsexual persons. NEngl J Med. 2011;364(13):1251-7. doi: 10.1056/NEJMcp1008161. [PubMed: 21449788].

12. Wierckx K, Van Caenegem E, Pennings G, Elaut E, Dedecker D, Van de Peer F, et al. Reproductive wish in transsexual men. Hum Reprod. 2012;27(2):483-7. doi: 10.1093/humrep/der406. [PubMed: 22128292].

13. Kuhn A, Bodmer C, Stadlmayr W, Kuhn P, Mueller MD, Birkhauser M. Quality of life 15 years after sex reassignment surgery for transsexualism. Fertil Steril. 2009;92(5):1685-1689 e3. doi: 10.1016/j.fertnstert.2008.08.126. [PubMed: 18990387].

14. Hejazi A, Edalati Shateri Z, Mostsfsvi SS, Hoseyni ZS, Razaghiyan M, Moghadam M. [Assessment of compliance with gender roles and sexual identity 12 teranssexual patients with new genders after sex reassignment surgery].J Kurdistan Univ Med Sci. 2009;13:78-87. Persian.

15. Rossi Neto R, Hintz F, Krege S, Rubben H, Vom Dorp F. Gender reassignment surgery-a 13 year review of surgical outcomes. Int Braz JUrol. 2012;38(1):97-107. doi: 10.1590/s1677-55382012000100014. [PubMed: 22397771].

16. Soli M, Brunocilla E, Bertaccini A, Palmieri F, Barbieri B, Martorana G. Male to female gender reassignment: Modified surgical technique for creating the neoclitoris and mons veneris. J Sex Med. 2008;5(1):210-6. doi: 10.1111/j.1743-6109.2007.00632.x. [PubMed:17956556].

17. Condous G, Jones R, Lam AM. Male-to-female transsexualism: Laparoscopic pelvic floor repair of prolapsed neovagina. Aust N Z J Obstet Gynaecol. 2006;46(3):254-6. doi: 10.1111/j.1479-828X.2006.00571.X. [PubMed: 16704484].

18. Baranyi A, Piber D, Rothenhausler HB. [Male-to-female transsexualism. Sex reassignment surgery from a biopsychosocial perspective]. Wien Med Wochenschr. 2009;159(21-22):548-57. German. doi: 10.1007/s10354-009-0693-5. [PubMed: 19997841]. 
19. De Stefani S, Trombetta C, Raber M, Savaco G, Moro U, Belgrano E. Microlaparoscopy in sex reassignment surgery. ScientificWorldjournal. 2004;4 Suppl 1:100-2. doi: 10.1100/tsw.2004.53. [PubMed: 15349534]. [PubMed Central: PMC5956464].

20. Klein C, Gorzalka BB. Sexual functioning in transsexuals following hormone therapy and genital surgery: A review. J Sex Med. 2009;6(11):2922-39. quiz 2940-1. doi: 10.1111/j.1743-6109.2009.01370.x. [PubMed: 20092545].

21. Bockting W, Coleman E, Deutsch MB, Guillamon A, Meyer I, Meyer W3, et al. Adult development and quality of life of transgender and gender nonconforming people. Curr Opin Endocrinol Diabetes Obes. 2016;23(2):188-97. doi: 10.1097/MED.0000000000000232. [PubMed: 26835800]. [PubMed Central: PMC4809047].

22. Javaheri F, Hoseinzadeh M. Social consequences GID: Social capital and quality of life of transsextualism in Iran. Iran J Soc Stud. 2011;5(3):19.

23. Ainsworth TA, Spiegel JH. Quality of life of individuals with and without facial feminization surgery or gender reassignment surgery. Qual Life Res. 2010;19(7):1019-24. doi: 10.1007/s11136-010-9668-7. [PubMed: 20461468].

24. Newfield E, Hart S, Dibble S, Kohler L. Female-to-male transgender quality of life. Qual Life Res. 2006;15(9):1447-57. doi:10.1007/s11136-0060002-3. [PubMed: 16758113].

25. Rakic Z, Starcevic V, Maric J, Kelin K. The outcome of sex reassignment surgery in Belgrade: 32 patients of both sexes. Arch Sex Behav. 1996;25(5):515-25. [PubMed: 8899143].

26. Lawrence AA. Factors associated with satisfaction or regret following male-to-female sex reassignment surgery. Arch Sex Behav. 2003;32(4):299-315. [PubMed: 12856892].

27. Rehman J, Lazer S, Benet AE, Schaefer LC, Melman A. The reported sex and surgery satisfactions of 28 postoperative male-to-female transsexual patients. Arch Sex Behav.1999;28(1):71-89. [PubMed: 10097806].

28. Lothstein LM. Psychological testing with transsexuals: A 30-year review. J Pers Assess. 1984;48(5):500-7. doi: 10.1207/s15327752jpa4805_9. [PubMed: 6389823]

29. Vasegh Rahimparvar F, Mousavi MS, Rayisi F, Khodabandeh F, Bahrani N. Comparison of quality of life in gender identity disorders after sex reassignment surgery with normal women in Tehran, Iran, 2012. Iran J Obstetr Gynecol Infertil. 2013;16(74):10-9.

30. Dhejne $\mathrm{C}$, Lichtenstein $\mathrm{P}$, Boman $\mathrm{M}$, Johansson $\mathrm{AL}$, Langstrom $\mathrm{N}$, Landen M. Long-term follow-up of transsexual persons undergoing sex reassignment surgery: Cohort study in Sweden. PLoS One. 2011;6(2). e16885. doi: 10.1371/journal.pone.0016885. [PubMed: 21364939]. [PubMed Central: PMC3043071].

31. Hess J, Rossi Neto R, Panic L, Rubben H, Senf W. Satisfaction with male-to-female gender reassignment surgery. Dtsch Arztebl Int. 2014;111(47):795-801. doi: 10.3238/arztebl.2014.0795. [PubMed: 25487762]. [PubMed Central: PMC4261554].

32. De Cuypere G, T'Sjoen G, Beerten R, Selvaggi G, De Sutter P, Hoebeke $P$, et al. Sexual and physical health after sex reassignment surgery. Arch Sex Behav. 2005;34(6):679-90. doi: 10.1007/s10508-005-7926-5. [PubMed: 16362252].

33. von Elm E, Altman DG, Egger M, Pocock SJ, Gotzsche PC, Vandenbroucke JP, et al. Strengthening the reporting of observational studies in epidemiology (STROBE) statement: Guidelines for reporting observational studies. BMJ. 2007;335(7624):806-8. doi: 10.1136/bmj.39335.541782.AD. [PubMed: 17947786]. [PubMed Central: PMC2034723].

34. Wu J, Ma J, Zhang WH, Di W. Management and outcomes of pregnancy with or without lupus nephritis: A systematic review and meta-analysis. Ther Clin Risk Manag. 2018;14:885-901. doi: 10.2147/TCRM.S160760. [PubMed: 29785115]. [PubMed Central: PMC5955382]

35. Cardoso da Silva D, Schwarz K, Fontanari AM, Costa AB, Massuda R, Henriques AA, et al. WHOQOL-100 before and after sex reassignment surgery in Brazilian male-to-female transsexual individuals. J Sex Med. 2016;13(6):988-93. doi:10.1016/j.jsxm.2016.03.370. [PubMed: 27117529]

36. Castellano E, Crespi C, Dell'Aquila C, Rosato R, Catalano C, Mineccia $\mathrm{V}$, et al. Quality of life and hormones after sex reassignment surgery. J Endocrinol Invest. 2015;38(12):1373-81. doi: 10.1007/s40618-015-0398-0. [PubMed: 26486135].

37. Davey A, Bouman WP, Arcelus J, Meyer C. Social support and psychological well-being in gender dysphoria: A comparison of patients with matched controls. J Sex Med. 2014;11(12):2976-85. doi: 10.1111/jsm.12681. [PubMed: 25155247].

38. Jokic-Begic N, Lauri Korajlija A, Jurin T. Psychosocial adjustment to sex reassignment surgery: A qualitative examination and personal experiences of six transsexual persons in croatia. ScientificWorldJournal.2014;2014:960745. doi: 10.1155/2014/960745. [PubMed: 24790589]. [PubMed Central: PMC3984784].

39. de Vries AL, McGuire JK, Steensma TD, Wagenaar EC, Doreleijers TA Cohen-Kettenis PT. Young adult psychological outcome after puberty suppression and gender reassignment. Pediatrics. 2014;134(4):696704. doi: 10.1542/peds.2013-2958. [PubMed: 25201798].

40. Motmans J, Meier P, Ponnet K, T'Sjoen G. Female and male transgender quality of life: Socioeconomic and medical differences. J Sex Med. 2012;9(3):743-50. doi: 10.1111/j.1743-6109.2011.02569.x. [PubMed: 22188877].

41. Wierckx K, Van Caenegem E, Elaut E, Dedecker D, Van de Peer F, Toye K, et al. Quality of life and sexual health after sex reassignment surgery in transsexual men. J Sex Med. 2011;8(12):3379-88. doi: 10.1111/j.17436109.2011.02348.x. [PubMed: 21699661].

42. Parola N, Bonierbale M, Lemaire A, Aghababian V, Michel A, Lançon C. Study of quality of life for transsexuals after hormonal and surgical reassignment. Sexologies. 2010;19(1):24-8. doi: 10.1016/j.sexol.2009.05.004.

43. Weyers S, Elaut E, De Sutter P, Gerris J, T’Sjoen G, Heylens G, et al. Longterm assessment of the physical, mental, and sexual health among transsexual women. J Sex Med. 2009;6(3):752-60. doi: 10.1111/j.17436109.2008.01082.x. [PubMed: 19040622].

44. Lawrence AA. Patient-reported complications and functional outcomes of male-to-female sex reassignment surgery. Arch Sex Behav. 2006;35(6):717-27. doi: 10.1007/s10508-006-9104-9. [PubMed: 17109225].

45. Modarresi Fard F, Kamkar A, Pour AM, Mirjalali PB. The effects of sex reassignment surgery (SRS) on gender schemata, personality and quality of life of patients with gender identity disorder. Reef resources assessment and management technical paper.J Sex Med. 2014;4(1):10.

46. Moher D, Liberati A, Tetzlaff J, Altman DG, Prisma Group. Preferred reporting items for systematic reviews and meta-analyses: The PRISMA statement. Ann Intern Med.2009;151(4):264-9. W64. doi:10.7326/00034819-151-4-200908180-00135. [PubMed: 19622511].

47. Doornaert M, Hoebeke P, Ceulemans P, T'Sjoen G, Heylens G, Monstrey S. Penile reconstruction with the radial forearm flap: An update. Handchir Mikrochir Plast Chir. 2011;43(4):208-14. doi: 10.1055/s-00301267215. [PubMed: 21837613].

48. Kuhn A, Santi A, Birkhauser M. Vaginal prolapse, pelvic floor function, and related symptoms 16 years after sex reassignment surgery in transsexuals. Fertil Steril. 2011;95(7):2379-82. doi: 10.1016/j.fertnstert.2011.03.029. [PubMed: 21458798].

49. Crall CS, Jackson RK. Should psychiatrists prescribe gender-affirming hormone therapy to transgender adolescents? AMA J Ethics. 2016;18(11):1086-94. doi: 10.1001/journalofethics.2016.18.11.ecas31611. [PubMed: 27883300].

50. Ghazanfarpour M, Sadeghi R, Roudsari RL. The application of soy isoflavones for subjective symptoms and objective signs of vaginal atrophy in menopause: A systematic review of randomised controlled trials. J Obstet Gynaecol. 2016;36(2):160-71. doi: 10.3109/01443615.2015.1036409. [PubMed: 26440219]. 


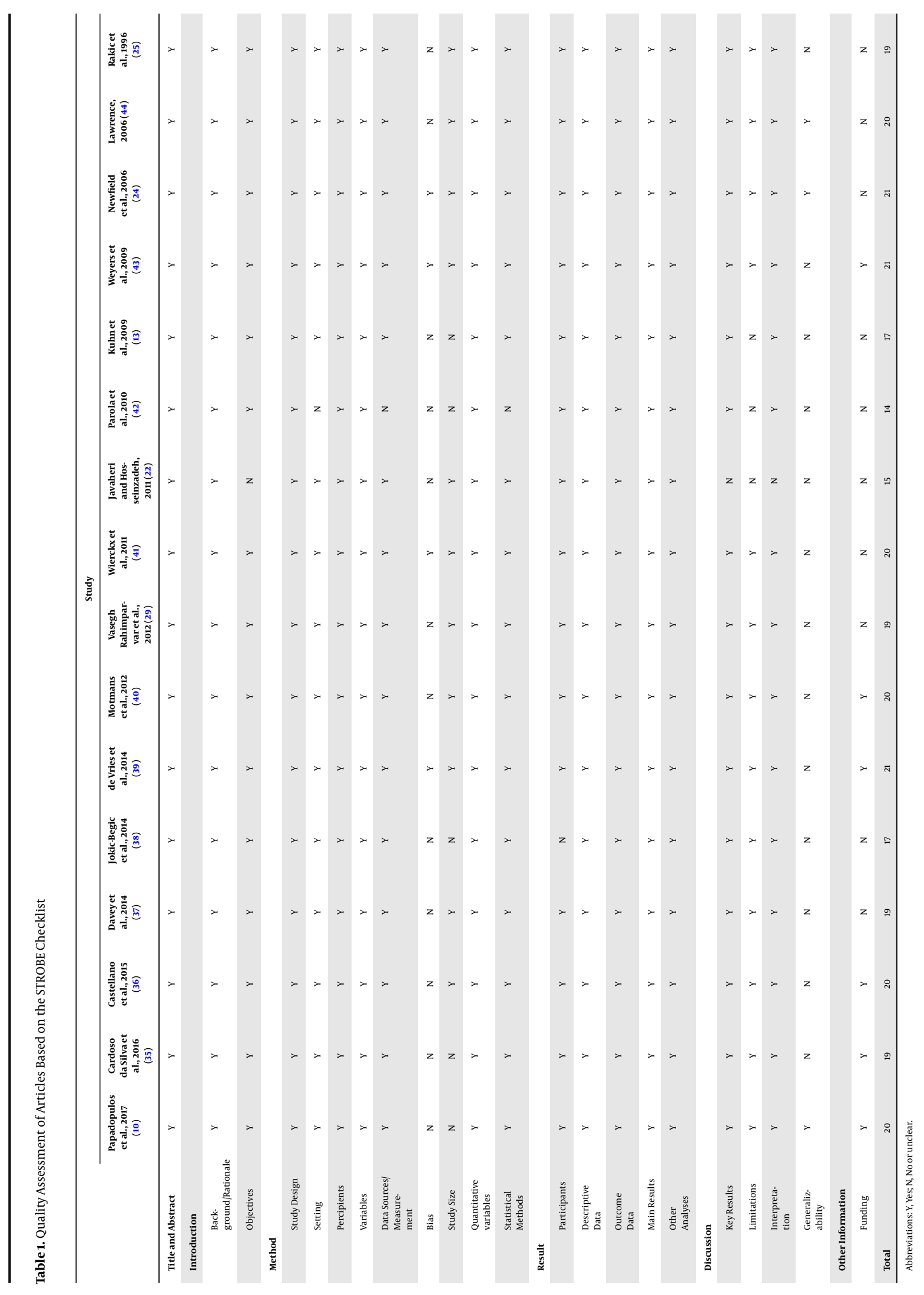

